\begin{tabular}{|c|c|}
\hline Title & $\begin{array}{l}\text { Electrocataly tic nitrate reduction on well-defined surfaces of tin-modified platinum, palladium and platinum-palladium } \\
\text { single crystalline electrodes in acidic and neutral media }\end{array}$ \\
\hline Author(s) & Kato, Masaru; Okui, Manabu; Taguchi, Satoshi; Y agi, Ichizo \\
\hline Citation & $\begin{array}{l}\text { Journal of Electroanalytical Chemistry, 800, 46-53 } \\
\text { https://doi.org/10.1016/.jelechem.2017.01.020 }\end{array}$ \\
\hline Issue Date & 2017-09-01 \\
\hline Doc URL & http:/hdl.handle.net/2115/79351 \\
\hline Rights & $\begin{array}{l}\text { (9 2017. This manuscript version is made available under the CC-BY -NC-ND } 4.0 \text { license } \\
\text { http://reativecommons.org/icenses/by-nc-nd/4.0/ }\end{array}$ \\
\hline Rights(URL) & http://creativecommons.org/icenses/by-nc-nd/4.0/ \\
\hline Type & article (author version) \\
\hline File Information & JEAC_SnPtPd_NO3_reduction.pdf \\
\hline
\end{tabular}

Instructions for use 


\title{
Electrocatalytic nitrate reduction on well-defined surfaces of tin-modified platinum, palladium and platinum-palladium single crystalline electrodes in acidic and neutral media
}

\author{
Masaru Kato, ${ }^{\mathrm{a}, \mathrm{b} *}$ Manabu Okui, ${ }^{\mathrm{b}}$ Satoshi Taguchi, ${ }^{\mathrm{c}}$ Ichizo Yagi $^{\mathrm{a}, \mathrm{b} *}$
}

${ }^{a}$ Faculty of Environmental Earth Science, Hokkaido University, N10W5, Kita-ku, Sapporo 060-0810, Japan. ${ }^{\mathrm{b}}$ Graduate School of Environmental Science, Hokkaido University, N10W5, Kita-ku, Sapporo 060-0810, Japan. ' Laboratory of Chemistry, Hokkaido University of Education Sapporo, Ainosato 5-3-1, Kita-ku, Sapporo 002-8502, Japan

Corresponding authors: masaru.kato@ees.hokudai.ac.jp (MK); iyagi@ees.hokudai.ac.jp (IY)

\begin{abstract}
Nitrate anion is one of the main nitrogen-containing-pollutants in groundwater and can be removed using denitrification systems including electrocatalytic systems. Herein we report on electrocatalytic nitrate reduction catalyzed on tin-modified single crystalline electrodes of palladium, platinum and palladium-platinum alloy in acidic and neutral media. We have prepared electrodes with the (111) surface or the (100) surface and modified their surface with tin. Cyclic voltammetry of the electrodes has revealed that the tin-modified alloy (trimetallic) electrodes show higher electrocatalytic activity than the tin-modified platinum or palladium (bimetallic) electrodes, and the catalytic reaction is more efficiently catalyzed on the (100) surface rather than the (111) surface. The tin-modified PdPt(100) electrode shows the highest catalytic activity in acidic media as well as in neutral media. X-ray photoelectron spectroscopy suggests that metallic tin forms on the (100) surface, but divalent tin species on the (111) surface, indicating that a surface alloy of tin may form on the (100) surface, resulting in enhancement of the electrocatalytic activity. Our findings suggest that design and preparation of ternary metallic electrodes with the (100) surface will pave the way to the development of practical systems on electrocatalytic denitrification.
\end{abstract}




\section{Research highlights}

- Tin-modified single crystalline Pd, Pt and Pd-Pt alloy electrodes are prepared.

- Electrocatalytic nitrate reduction occurs efficiently on the (100) surface.

- A surface alloy may form for Sn/PdPt(100), revealed by using XPS.

- Sn/PdPt(100) is highly active for electrocatalytic nitrate reduction.

- Sn/PdPt(100) shows the catalytic activity in not only acidic but also neutral media.

Keywords: Denitrification; Electrocatalysts; Single crystalline electrodes; Nitrate reduction; Platinum; Palladium.

\section{Graphical abstract}

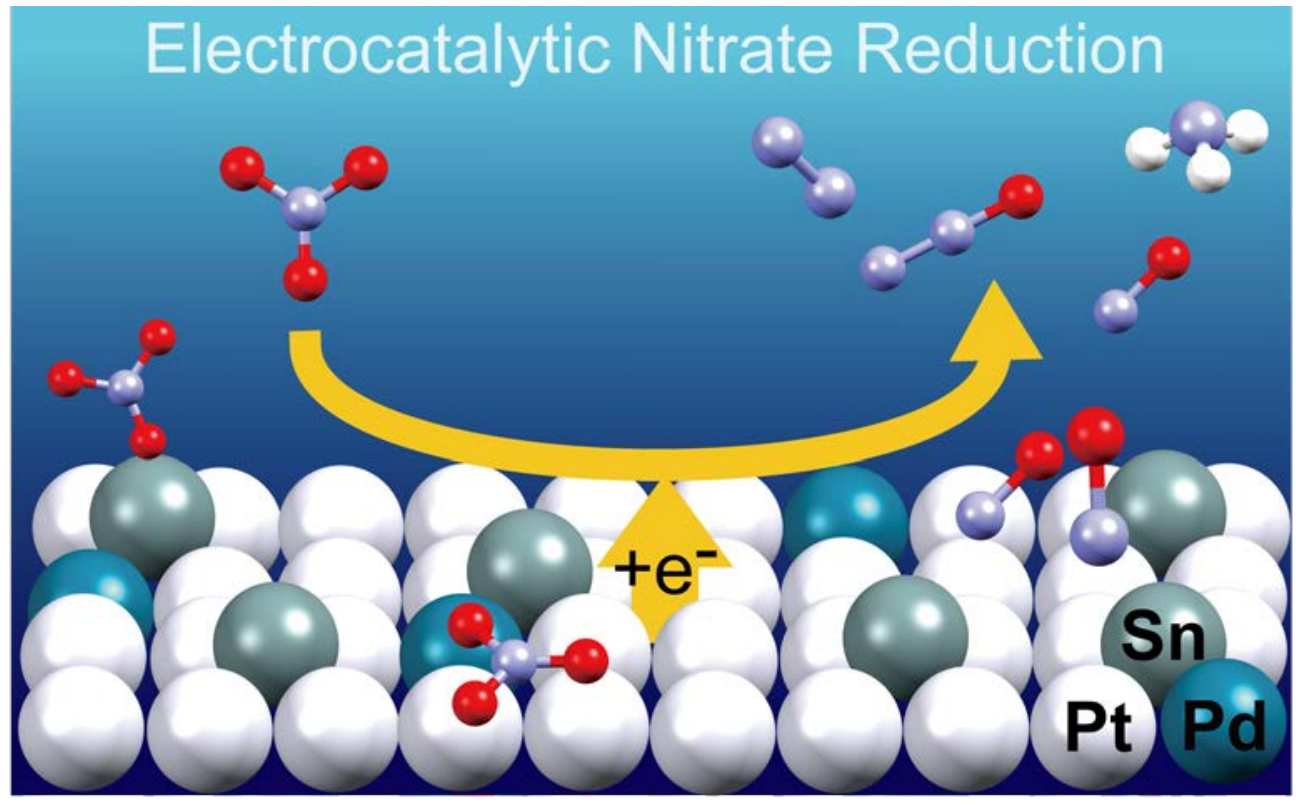




\section{Introduction}

Nitrate is the main nitrogen-containing pollutant in groundwater and is removed in the natural denitrification process, where nitrate is reduced to harmless dinitrogen gas by denitrifying bacteria [1-5]. Fertilizer-intensive agriculture causes imbalances in the nitrogen cycle and then an increase in the concentration of nitrate ions in groundwater. The excess nitrate ions in groundwater have raised a widespread concern for eutrophication of water reservoirs, and health threats including methemoglobinemia (blue baby syndrome) and cancer [4,5]. Therefore, efficient removal systems of nitrate ions from an aqueous solution containing nitrate are highly required.

Electrocatalytic denitrification is one of the promising approaches to remove nitrate ions from nitrate-contaminated water. A biological denitrification is the most widespread approach, in which bacteria convert $\mathrm{NO}_{3}{ }^{-}$to the harmless product of $\mathrm{N}_{2}$ as long as bacterial growth conditions are maintained. In the biological denitrification system, pathogenic bacteria could be developed, which is a serious issue for the industrial denitrification system $[2,4,5]$. In contrast, electrocatalytic denitrification systems require electrodes, which are based on inorganic materials and have no concern for the development of the pathogenic bacteria. Furthermore, the electrocatalytic denitrification can be powered by renewable energy such as solar light [6-9] and wind power, leading to environmentally friendly removing nitrate ions from drinking water sources.

Electrocatalytic denitrification systems have been studied using various electrodes such as metals [10,11], binary metals (adatoms and alloys) [12-22], metal nanoparticles [2326], metal complexes [27-30] and metalloenzymes [3,31-33]. Although the nitrate reduction activity of monometallic electrodes including platinum and palladium has been intensively studied, these monometallic electrodes themselves are known to show poor electrocatalytic activity. To improve their catalytic activity, influences of the combination of other metals $[12,21,22,24]$ or the surface modification with a "promoter" such as tin [13-15,34] on the nitrate reduction activity has been investigated. These treatments are able to accelerate the rate-determining step of the reduction of $\mathrm{NO}_{3}{ }^{-}$to nitrite $\left(\mathrm{NO}_{2}{ }^{-}\right)$. 
Palladium is one of the most promising metal electrodes for nitrate reduction because palladium is able to produce the most desirable product of $N_{2}[5,35,36]$. Furthermore, the combination of $\mathrm{Pt}$ or $\mathrm{Pd}$ with a promoter of $\mathrm{Sn}$ drastically enhances the electrocatalytic activity and the activity of the Sn-Pt or Sn-Pd is enough for practical applications in acidic media $[13,15,34,37]$. However, from the viewpoint of practical applications such as the decontamination of groundwater, the use of neutral media is relevant $[23,38]$. Interestingly, $\mathrm{Pt}(100)$ catalyzes nitrate reduction in not only acidic but also neutral media, whereas $\operatorname{Pt}(111)$ shows the activity only in acidic media [23]. Furthermore, $\operatorname{Pt}(100)$ is the most active surface for breaking the $\mathrm{N}-\mathrm{O}$ bond revealed under UHV conditions [39] and the (100) surface is ideal for a Langmuir-Hinshelwood-type reaction between $\left(\mathrm{NH}_{x}\right)_{\text {ads }}$ and $\mathrm{NO}_{\text {ads }}$ [5]. Thus, further studies on the electrocatalytic activity on the (100) surface of metal electrodes would allow us to develop practical electrocatalysts for denitrification.

Herein we report effects of surface structures and compositions of single crystalline electrodes modified with tin on electrocatalytic nitrate reduction activity. We have prepared monometallic platinum and palladium single crystalline electrodes and bimetallic palladium-platinum alloy single crystalline electrodes and then modified their surfaces with tin. In this work, the electrodes with the (111) or the (100) basal plane are used because tin irreversibly adsorbs on $\operatorname{Pt}(111)$ and $\operatorname{Pt}(100)$ [40]. Electrochemical nitrate reduction on the well-defined surfaces has been studied not only in acidic media but also neutral media to gain insights into developing denitrification electrocatalysts.

\section{Experimental}

\subsection{Materials}

Perchloric acid (70\%, purity: 99.999\%; Sigma-Aldrich Co.), sulfuric acid (96.0\%, Wako Pure Chemical Industries, Ltd.), tin(II) chloride dihydrate (97.0\%, Kanto Chemical Co., Inc.) and sodium nitrate (99.99, Kanto Chemical Co., Inc.) were purchased and used without further purification. Platinum wires (0.8 $\mathrm{mm} \phi$ or $0.5 \mathrm{~mm} \phi ; 99.99 \%$ purity) and palladium (0.8 $\mathrm{mm} \phi$ or $0.5 \mathrm{~mm} \phi$; $99.99 \%$ purity) wires were used for the preparation of single crystalline electrodes. 


\subsection{Preparation of well-defined single crystalline electrodes}

Pt, Pd and PdPt alloy single crystalline beads were prepared based on the procedure reported by Clavilier and co-workers [41-43]. A platinum wire or a palladium wire was annealed in methane-oxygen flame to obtain a single crystalline bead at the end of the wire. For the preparation of Pt-Pd alloy single crystalline beads, the single crystalline bead of Pt was used as a seed crystal as well as the source of Pt, and an amount of Pd was added to the Pt bead in methane-oxygen flame [44-46]. The percentage of Pd in Pt was controlled by the amount of Pd added. In this study, we prepared PdPt alloy electrodes with $3 \mathrm{wt} \%$ of Pd in Pt.

The single crystalline beads were oriented using the reflection of a He-Ne laser beam from a (111) facet or a (100) facet on the single crystalline bead, fixed in a poly(methyl methacrylate) resin (Technovit 4004, Heraeus Kulzer), cut in the direction of the (111) facet or the (100) facet, and then polished with diamond slurries to be mirror-finished. The polished single crystalline electrode was annealed in methane-oxygen flame at $<1250^{\circ} \mathrm{C}$ for four hours. To confirm the preparation of the single crystalline electrode with a specific orientation, cyclic voltammograms (CVs) were recorded in $0.5 \mathrm{M}$ $\mathrm{H}_{2} \mathrm{SO}_{4}$ aqueous solution under Ar.

\subsection{Electrochemical measurements}

The Pt single crystalline electrodes were annealed in $\mathrm{H}_{2}-\mathrm{O}_{2}$ flame or in the induction coil of an induction heating system (EASY-HEAT, Ambrell model 0224), cooled under Ar, and then immersed in Milli-Q water purged with Ar. The surface of the electrode was covered with Milli-Q water and then transferred to the electrochemical cell for electrochemical measurements. Similarly, Pd and PdPt alloy single crystalline electrodes were annealed using the induction heating system, cooled under $\mathrm{H}_{2}-\mathrm{Ar}$, immersed in Milli-Q water under $\mathrm{H}_{2}-\mathrm{Ar}$, and then transferred to the electrochemical cell under the protection of a droplet of Milli-Q water for electrochemical measurements.

All electrochemical data were recorded on potentiostats (HZ5000 and HZ7000, Hokuto 
Denko Corp.) using conventional three-electrode systems under $\operatorname{Ar}$ (99.999\%, HOKKAIDO AIR WATER INC.). Single crystalline electrodes were used as working electrodes. A Ag|AgCl (sat. $\mathrm{KCl}$ ) electrode with a double junction holder (International chemistry Co., LTD) and platinum foil coated with platinum black were used as the reference electrode and the counter electrode, respectively. Electrolyte solutions were purged with Ar (99.999\%) for at least 30 min before measurements. All electrochemical measurements were performed in the hanging meniscus configuration. CVs on nitrate reduction were recorded in a $0.1 \mathrm{M} \mathrm{HClO}_{4}$ aqueous solution containing $0.1 \mathrm{M} \mathrm{NaNO}_{3}$ at a sweep rate of $10 \mathrm{mV} \mathrm{s}^{-1}$ under Ar or in $0.05 \mathrm{M}$ phosphate buffered aqueous solution containing $0.1 \mathrm{M} \mathrm{NaNO}_{3}$ at $\mathrm{pH} 7.2$ at a sweep rate of $50 \mathrm{mV} \mathrm{s}^{-1}$ under Ar. All potentials in the main text are shown against the reversible hydrogen electrode (RHE). The potentials against $\mathrm{Ag} \mid \mathrm{AgCl}$ (sat. $\mathrm{KCl}$ ) were converted to those against RHE using the following equation: $E$ (vs. RHE) $=E($ vs. Ag| $\mathrm{AgCl}($ sat. $\mathrm{KCl}))+0.199+0.059 \times \mathrm{pH}$.

The surface modification of single crystalline electrodes with tin was carried out based on a reported procedure $[16,19]$. The annealed single crystalline electrode covered with a droplet of Milli-Q water was immersed in $0.1 \mathrm{M} \mathrm{HClO}_{4}$ aqueous solution containing $\mathrm{SnCl}_{2}$. The surface coverage was controlled by the $\mathrm{SnCl}_{2}$ concentration $(0.1 \mathrm{mM}-0.5$ $\mathrm{mM}$ ) and the immersion time (10 s-30 s). After the immersion, the electrode was immediately transferred to an electrochemical cell under the protection of a droplet of the $\mathrm{SnCl}_{2}$ solution. CVs of tin-modified electrodes in the $\mathrm{H}_{\text {upd }}$ desorption region in 0.5 $\mathrm{M} \mathrm{H}_{2} \mathrm{SO}_{4}$ aqueous solution allowed us to determine the tin surface coverage $\left(\theta_{\mathrm{Sn}}\right)$ using the following equation: $\theta_{S n}=\left(Q_{H}^{0}-Q_{H}\right) / Q_{H}^{0}$, where $Q_{H}^{0}$ and $Q_{H}$ indicate the Faradaic charges corresponding to the desorption of $\mathrm{H}_{\text {upd }}$ before and after the tin modification, respectively.

\subsection{X-ray photoelectron spectroscopy}

X-ray photoelectron spectroscopy (XPS) of single crystalline electrodes was performed on a photoelectron spectrometer XPS7000 (Rigaku). Mg Ka was used as the X-ray source. The peak of $\mathrm{C}=\mathrm{C}$ at $284.7 \mathrm{eV}$ in the $\mathrm{C} 1$ s region was used as the internal standard to calibrate the binding energies of the elements. 


\section{Results and discussion}

\subsection{Preparation and characterization of single crystalline electrodes of platinum, palladium and palladium-platinum alloy}

Platinum, palladium and palladium-platinum alloy single crystalline electrodes were prepared based on the Clavilier method [41-43]. To characterize the prepared electrodes, their CVs were recorded in $0.5 \mathrm{M} \mathrm{H}_{2} \mathrm{SO}_{4}$ under Ar. Figure 1 shows CVs of single crystalline electrodes with well-defined (111) surfaces. The CV of the Pt(111) electrode showed adsorption/desorption peaks of underpotentially deposited hydrogen $\left(\mathrm{H}_{\text {upd }}\right)$ at $<+0.5 \mathrm{~V}$ vs. RHE and a spike involving a phase transition in the sulfate adlayer on Pt(111) surface at around $+0.42 \mathrm{~V}$ vs. RHE [43]. The CV of the Pd(111) electrode also shows sharp peaks in the potential range from +0.2 to $+0.3 \mathrm{~V}$ vs. RHE, originating from the sulfate adsorption and desorption [47]. These characteristic features allowed us to confirm the preparation of the well-defined Pt(111) and Pd(111) electrodes.

The PdPt(111) alloy single crystalline electrode with 3 wt\% of Pd in Pt was prepared, based on a previously reported method [44-46]. The well-defined single crystalline electrode was confirmed using cyclic voltammetry in $0.5 \mathrm{M} \mathrm{H}_{2} \mathrm{SO}_{4}$ under $\mathrm{Ar}$ (Fig. 1). The peak intensity of the characteristic spike observed for $\operatorname{Pt}(111)$ was decreased for the $\operatorname{PdPt}(111)$, suggesting that palladium atoms were randomly dispersed in the $\operatorname{PdPt}(111)$ alloy, because a randomly distributed solid solution phase was reported over the whole composition range in the phase diagram of bulk platinum and palladium $[13,48]$, where the long-range order of the $\operatorname{Pt}(111)$ terrace was lost $[44,46]$. The $\operatorname{PdPt}(111)$ single crystalline alloy showed peaks in the Pt $4 \mathrm{f}$ region as well as in the Pd 3d region in XPS spectra (Fig. 2), also indicating the successful incorporation of Pd into Pt(111).

Single crystalline Pt and PdPt alloy electrodes with the (100) surface were prepared and their CVs were recorded (Fig. 1). In the case of $\mathrm{Pt}(100)$, characteristic $\mathrm{H}_{\text {upd }}$ peaks were observed in the potential range from +0.2 to $+0.4 \mathrm{~V}$ vs. RHE [49]. The sharp peak at around $+0.35 \mathrm{~V}$ vs. RHE is associated with extended $(1 \times 1)-\mathrm{Pt}(100)$ long range order [46]. In the case of the $\operatorname{PdPt}(100)$ alloy single crystalline electrode, the sharp peak at around $+0.35 \mathrm{~V}$ vs. RHE was also observed but the peak intensity was lower compared 
with $\operatorname{Pt}(100)$. This change in peak intensity was caused by the formation of the $\operatorname{PdPt}(100)$ alloy single crystalline electrode. Furthermore, XPS spectra of the PdPt(100) showed peaks in the Pt $4 \mathrm{f}$ and Pd 3d regions (Fig. 3). Thus, these findings indicate the successful preparation of single crystalline $\operatorname{Pt}(100)$ and $\operatorname{PdPt}(100)$ electrodes.

\subsection{Surface modification of single crystalline electrodes with tin}

To modify the surface of single crystalline electrodes with tin, the electrodes were immersed in $0.1 \mathrm{M} \mathrm{HClO}_{4}$ aqueous solution containing $\mathrm{SnCl}_{2}$. Controlling the concentration of $\mathrm{SnCl}_{2}$ at $0.1 \mathrm{mM}$ to $0.5 \mathrm{mM}$ and the immersion time for $10 \mathrm{~s}$ to $30 \mathrm{~s}$ defined the surface coverage of tin. The surface coverage was determined based on the Faradaic charges corresponding to the $\mathrm{H}_{\text {upd }}$ desorption region in the CVs in $0.5 \mathrm{M}$ $\mathrm{H}_{2} \mathrm{SO}_{4}$ before and after the surface modification with tin (Fig. 1). Note that characteristic features of Pt or Pd in CVs disappeared when the surface coverage of tin was nearly 1 (See Fig. S1 in Supplementary material).

All tin-modified electrodes showed peaks in Sn 3d XPS spectra (Fig. 4), allowing us to confirm the surface modification with tin. A peak observed in the range from $490 \mathrm{eV}$ to $497 \mathrm{eV}$ in binding energy is associated with $\mathrm{Sn} 3 \mathrm{~d}_{3 / 2}$, whereas a peak in the range from $482 \mathrm{eV}$ to $488 \mathrm{eV}$ is associated with $\mathrm{Sn} 3 \mathrm{~d}_{5 / 2}$. The peak deconvolution analysis of the Sn 3d XPS spectra gave two components and the peaks at higher and lower binding energies were assigned to $\mathrm{Sn}^{\mathrm{II}}$ species and to $\mathrm{Sn}^{0}$ (metallic tin), respectively, because XPS Sn $3 d_{5 / 2}$ peaks are known to be observed at 486.1-488.2 eV for $\mathrm{Sn}^{\mathrm{IV}}$, 485.6-487.4 $\mathrm{eV}$ for $\mathrm{Sn}^{\mathrm{II}}$ and $484.3-485.2 \mathrm{eV}$ for $\mathrm{Sn}^{0}$ [15].

The peak deconvolution analysis allowed us to estimate the ratio of $\mathrm{Sn}^{\mathrm{II}}$ to $\mathrm{Sn}^{0}$ for the tin-modified electrodes (Table 1). It seems that the tin-modified electrodes with the (111) surface tend to have more $\mathrm{Sn}^{\mathrm{II}}$ species than $\mathrm{Sn}^{0}$ whereas more metallic tin was observed on the (100) surfaces than $\mathrm{Sn}^{\mathrm{II}}$ species. These results are in good agreement with DFT calculations, which suggest that metallic tin on $\mathrm{Pt}(111)$ surface is more easily oxidized than that on $\mathrm{Pt}(100)$ surface [50]. Note that simple tin deposition gives no metallic tin on polycrystalline platinum [13,51] or on polycrystalline palladium [16]. The difference in the oxidation state of tin species between tin-modified (111) and (100) 
electrodes may influence the electrocatalytic activity for nitrate reduction. The relationship between the oxidation state of tin and the electrocatalytic activity is discussed in Section 3.3.

\subsection{Electrocatalytic nitrate reduction on tin-modified single crystalline electrodes in acidic aqueous solution}

CVs of single crystalline electrodes unmodified with tin were recorded in an aqueous solution containing $0.1 \mathrm{M} \mathrm{HClO}_{4}$ and $0.1 \mathrm{M} \mathrm{NaNO}_{3}$ under $\mathrm{Ar}$ (Fig. 5). The bare single crystalline electrodes that we used except the bare $\operatorname{Pd}(111)$ electrode showed almost no current, indicating almost no catalytic activity for the nitrate reduction. Although cathodic and anodic currents were observed for the bare Pd(111) electrode, these currents are mainly due to the hydrogen adsorption/absorption and desorption, respectively $[10,14]$.

The tin-modification activated the surface of the single crystalline electrodes for nitrate reduction. The tin-modified electrodes showed cathodic currents in the electrolyte solution containing $0.1 \mathrm{M} \mathrm{HClO}_{4}$ and $0.1 \mathrm{M} \mathrm{NaNO}_{3}$ (Fig. 5) whereas no such current was observed in the absence of $0.1 \mathrm{M} \mathrm{NaNO}_{3}$ (Fig. S2), suggesting that electrocatalytic nitrate reduction occurred on the tin-modified surfaces. In the case of the $\operatorname{Sn} / \operatorname{Pd}(111)$ electrode, no oxidation peak corresponding to hydrogen oxidation was observed. Thus, the nitrate reduction also occurred on the $\mathrm{Sn} / \mathrm{Pd}(111)$ surface but hydrogen evolution or the oxidation of hydrogen in the bulk did not. These findings are in good agreement with those of tin-modified polycrystalline Pt and Pd electrodes previously reported $[15,17,34,52]$.

Interestingly, the $\mathrm{Sn} / \mathrm{Pt}(111)$ and $\mathrm{Sn} / \mathrm{PdPt}(111)$ electrodes with low tin coverage showed a cathodic peak at ca. $+0.08 \mathrm{~V}$ vs. RHE, whereas no peak was observed for those electrodes with high tin coverage and the other electrodes. The nitrate reduction may be deactivated on the $\mathrm{Sn} / \mathrm{Pt}(111)$ and $\mathrm{Sn} / \mathrm{PdPt}(111)$ surfaces with low tin coverage at $<$ $+0.12 \mathrm{~V}$ vs. RHE because of the strong adsorption of $H_{\text {upd }}$ on the surface $[17,37]$. It is known that $\mathrm{N}_{2} \mathrm{O}$ is the main product for tin-modified platinum electrodes with intermediate tin coverage, whereas NO is dominant with high tin coverage [37]. Thus, 
the nitrate reduction activity on the $\mathrm{Pt}(111)$ surface is quite sensitive to the $\mathrm{H}_{\text {upd }}$ adsorption and the reaction mechanism depends on the tin coverage on the $\operatorname{Pt}(111)$ surface. In contrast, no such cathodic peak was observed for $\mathrm{Sn} / \mathrm{Pt}(100)$, Sn/Pd(111) and $\mathrm{Sn} / \operatorname{PdPt}(100)$, implying that the $\mathrm{H}_{\text {upd }}$ adsorption was suppressed on electrodes containing palladium or possessing the (100) surface. On these surfaces, the reaction mechanism should be independent of the tin coverage.

Table 2 summarizes the maximum current densities shown by the tin-modified electrodes in the potential range between $+0.10 \mathrm{~V}$ and $+0.01 \mathrm{~V}$ vs. RHE. The nitrate reduction activity on the tin-modified electrodes tends to increase in the following order: Sn/Pt(111) Sn/Pd(111) < Sn/Pt(100) < Sn/PdPt(111) < Sn/PdPt(100). The $\mathrm{Sn} / \operatorname{PdPt}(100)$ electrode with $\theta_{\mathrm{Sn}}=0.81$ gave rise to the highest current density of -32.1 $\mathrm{mA} \mathrm{cm} \mathrm{cm}^{-2}$ at $+0.01 \mathrm{~V}$ vs. RHE for the electrocatalytic nitrate reduction (Table 2). Previously a tin-modified palladium thin film electrode with $\theta_{\mathrm{Sn}}=0.77$ showed $-10.3 \mathrm{~mA}$ $\mathrm{cm}^{-2}$ at $+0.16 \mathrm{~V}$ vs. RHE and its activity was the highest activity for electrocatalytic nitrate reduction at that time [15]. At $+0.16 \mathrm{~V}$ vs. RHE, a current density of $-12.4 \mathrm{~mA}$ $\mathrm{cm}^{-2}$ was observed for our $\operatorname{Sn} / \operatorname{PdPt}(100)$ electrode with $\theta_{\mathrm{Sn}}=0.81$. Thus, the $\operatorname{Sn} / \operatorname{PdPt}(100)$ electrode with $\theta_{\mathrm{Sn}}=0.81$ is highly active for the electrocatalytic nitrate reduction.

The order of the electrocatalytic activity revealed that the ternary metal electrodes were more active to electrocatalytic nitrate reduction than the binary metal electrodes. Thus, the combination of three metals of tin, palladium and platinum resulted in the enhancement of the electrocatalytic activity for the nitrate reduction. The combination of these metals might modulate the adsorption ability of nitrate anions to the surface [16] and/or the position of the $d$-band center [13].

The order of the electrocatalytic activity also suggests that the electrocatalytic nitrate reduction is more efficiently catalyzed on the tin-modified (100) surface rather than on the tin-modified (111) surface. The difference in the electrocatalytic activity between the tin-modified (100) electrodes and the tin-modified (111) electrodes may be related to the oxidation state of tin on the electrode substrate. As mentioned in Section 3.2, metallic tin was mainly observed for the tin-modified (100) electrodes but divalent tin 
species for the tin-modified (111) electrodes. Thus, a surface alloy of tin may form on the (100) surface, resulting in the enhancement of the electrocatalytic activity for the nitrate reduction. Similar results were reported on electrochemically pre-reduced tin-modified palladium electrodes [16], in which divalent tin species on a polycrystalline palladium were electrochemically reduced to metallic tin, resulting in the enhancement of the electrocatalytic activity for the nitrate reduction. Although further experimental studies are necessary to understand the origin of the high electrocatalytic activity of the $\mathrm{Sn} / \operatorname{PdPt}(100)$ electrode, the formation of a ternary metal alloy on the surface may accelerate the $\mathrm{N}-\mathrm{O}$ bond cleavage [16].

\subsection{Nitrate reduction in neutral media}

Electrocatalytic nitrate reduction on metal electrodes has been extensively studied in acidic media, whereas a few studies are reported in neutral media [23,38]. From a practical point of view, nitrate reduction electrocatalysts that are active not only in acidic media but also in neutral media should be developed because denitrification of nitrate-contaminated water waste or groundwater should be performed under neutral conditions rather than acidic conditions. In this work, we have also performed the electrocatalytic nitrate reduction experiments in neutral media. Our electrochemical studies in neutral media mainly focused on the $\operatorname{Pt}(100)$ and $\operatorname{PdPt}(100)$ electrodes unmodified/modified with tin $(\theta \approx 1)$ because the electrocatalytic activity of platinum is known to be extremely sensitive to the surface structure and the nitrate reduction occurs mainly on the well-defined (100) terraces [23].

Electrochemical measurements in neutral media revealed that the bare $\operatorname{Pt}(100)$ and $\operatorname{PdPt}(100)$ electrodes showed the electrocatalytic activity for the nitrate reduction, but the bare Pt(111) electrode did not (Fig. 6). A characteristic reduction peak was in the positive going sweep observed at ca. $+0.44 \mathrm{~V}$ vs. RHE for $\mathrm{Pt}(100)$ and at ca. $+0.39 \mathrm{~V}$ vs. RHE for $\operatorname{PdPt}(100)$. The electrochemical behavior of $\operatorname{Pt}(100)$ or $\operatorname{PdPt}(100)$ in neutral media is similar to that previously reported for $\operatorname{Pt}(100)$ [23]. This characteristic reduction peak can be assigned to nitrate reduction at the (100) terrace sites with low $\mathrm{H}_{\text {upd }}$ coverage [23]. An oxidation peak was also observed for $\operatorname{Pt}(100)$ and $\operatorname{PdPt}(100)$ at $>+0.8 \mathrm{~V}$ vs. RHE in the positive going scan, indicating the re-oxidation of nitrate 
reduction products. This oxidation process might involve reactions on hyponitrous acid [23].

After the surface modification of the (100) surface with tin $(\theta \approx 1)$, the nitrate reduction activity was drastically enhanced for $\operatorname{PdPt}(100)$. The $\operatorname{Sn} / \operatorname{PdPt}(100)$ showed cathodic currents at <+0.4 V vs. RHE for $\operatorname{PdPt}(100)$ in the phosphate buffered solution containing $\mathrm{NaNO}_{3}$ (Fig. 6) whereas no such cathodic currents were observed in the absence of $\mathrm{NaNO}_{3}$ (Fig. S3), suggesting that nitrate reduction occurred on the $\mathrm{Sn} / \operatorname{PdPt}(100)$ surface in neutral media. Interestingly, the characteristic cathodic peak that was observed in the positive going scan for the unmodified PdPt(100) disappeared. Although further studies are required to conclude the reaction mechanism on the surface of $\mathrm{Sn} / \mathrm{PdPt}(100)$ in neutral media, the tin surface modification might suppress the competitive adsorption of $\mathrm{H}_{\text {upd }}$ and nitrate on the surface, resulting in the enhancement of the catalytic activity.

\section{Conclusions}

The tin-modified single crystalline electrodes of Pt, Pd and PdPt alloy with the (111) surface or the (100) surface showed electrocatalytic activity for the nitrate reduction in acid media and the tin-modified $\operatorname{PdPt}(100)$ electrode showed the highest catalytic activity. The tin-modified $\operatorname{PdPt}(100)$ electrode also catalyzed the nitrate reduction even in neutral media, suggesting that ternary metallic electrodes with the well-defined (100) surface will provide new possibilities for applications to electrocatalytic denitrification. XPS measurements of the tin-modified electrodes allowed us to confirm that divalent tin species were deposited on the (111) surfaces whereas metallic tin was the main species on the (100) surfaces.

Although the reaction mechanism or the enhancement mechanism for the nitrate reduction remains still unclear, it is most likely that the formation of the ternary metallic surface alloy is associated with the high electrocatalytic activity for the nitrate reduction in acidic media as well as in neutral media. To understand the reaction mechanism in detail, the product analysis using online-mass spectroscopy (also called differential electrochemical mass spectroscopy, DEMS) and ion chromatography is underway in our 
group.

\section{Acknowledgements.}

The authors would like to thank Takao Ohta (the Technical Division, Research Institute for Electronic Science, Hokkaido University), Katsuhisa Ishikawa (the Technical Division, Institute for Catalysis, Hokkaido University) and Takahiko Hasegawa (the Technical Division, Institute for Catalysis, Hokkaido University) for technical supports on electrochemical cells. We also thank Shingo Mukai (the Technical Division, Institute for Catalysis, Hokkaido University) for technical supports on the preparation of single crystalline electrodes. This work was partially supported by Grant-in-Aid for Young Scientists (B) (No. 16K20882 to MK) and Grant-in-Aid for Challenging Exploratory Research (No. 15K13612 to IY). 


\section{References}

[1] D.M. Manassaram, L.C. Backer, D.M. Moll, A review of nitrates in drinking water: maternal exposure and adverse reproductive and developmental outcomes., Environ. Health Perspect. 114 (2006) 320-327. doi:10.1289/ehp.8407.

[2] J.Y. Park, Y.J. Yoo, Biological nitrate removal in industrial wastewater treatment: which electron donor we can choose, Appl. Microbiol. Biotechnol. 82 (2009) 415-429. doi:10.1007/s00253-008-1799-1.

[3] P. Tavares, A.S. Pereira, J.J.G. Moura, I. Moura, Metalloenzymes of the denitrification pathway, J. Inorg. Biochem. 100 (2006) 2087-2100. doi:10.1016/j.jinorgbio.2006.09.003.

[4] K.A. Karanasios, I.A. Vasiliadou, S. Pavlou, D.V. Vayenas, Hydrogenotrophic denitrification of potable water: A review, J. Hazard. Mater. 180 (2010) 20-37. doi:10.1016/j.jhazmat.2010.04.090.

[5] M. Duca, M.T.M. Koper, Powering denitrification: the perspectives of electrocatalytic nitrate reduction, Energy Environ. Sci. 5 (2012) 9726-9742. doi:10.1039/c2ee23062c.

[6] J. Hirayama, R. Abe, Y. Kamiya, Combinational effect of Pt/SrTiO $: \mathrm{Rh}$ photocatalyst and $\mathrm{SnPd} / \mathrm{Al}_{2} \mathrm{O}_{3}$ non-photocatalyst for photocatalytic reduction of nitrate to nitrogen in water under visible light irradiation, Appl. Catal. B Environ. 144 (2014) 721-729. doi:10.1016/j.apcatb.2013.08.005.

[7] H. Gekko, K. Hashimoto, H. Kominami, Photocatalytic reduction of nitrite to dinitrogen in aqueous suspensions of metal-loaded titanium(iv) oxide in the presence of a hole scavenger: an ensemble effect of silver and palladium co-catalysts, Phys. Chem. Chem. Phys. 14 (2012) 7965. doi:10.1039/c2cp40729a.

[8] J. Hirayama, Y. Kamiya, Combining the Photocatalyst $\mathrm{Pt} / \mathrm{TiO}_{2}$ and the 
Nonphotocatalyst $\mathrm{SnPd} / \mathrm{Al}_{2} \mathrm{O}_{3}$ for Effective Photocatalytic Purification of Groundwater Polluted with Nitrate, ACS Catal. 4 (2014) 2207-2215. doi:10.1021/cs5003564.

[9] M. Yue, R. Wang, N. Cheng, R. Cong, W. Gao, T. Yang, $\mathrm{ZnCr}_{2} \mathrm{~S}_{4}$ : Highly effective photocatalyst converting nitrate into $\mathrm{N}_{2}$ without over-reduction under both UV and pure visible light, Sci. Rep. 6 (2016) 30992.

doi:10.1038/srep30992.

[10] G. Dima, A.C. de Vooys, M.T. Koper, Electrocatalytic reduction of nitrate at low concentration on coinage and transition-metal electrodes in acid solutions, J. Electroanal. Chem. 554-555 (2003) 15-23. doi:10.1016/S0022-0728(02)01443-2.

[11] S. Taguchi, J.M. Feliu, Electrochemical reduction of nitrate on $\operatorname{Pt}(\mathrm{S})[\mathrm{n}(111) \times(111)]$ electrodes in perchloric acid solution, Electrochim. Acta. 52 (2007) 6023-6033. doi:10.1016/j.electacta.2007.03.057.

[12] J. Souza-Garcia, E.A. Ticianelli, V. Climent, J.M. Feliu, Mechanistic changes observed in heavy water for nitrate reduction reaction on palladium-modified Pt(hkl) electrodes, Chem. Sci. 3 (2012) 3063. doi:10.1039/c2sc20490h.

[13] J. Yang, F. Calle-Vallejo, M. Duca, M.T.M. Koper, Electrocatalytic reduction of nitrate on a Pt electrode modified by p-block metal adatoms in acid solution, ChemCatChem. 5 (2013) 1773-1783. doi:10.1002/cctc.201300075.

[14] Y.Y. Birdja, J. Yang, M.T.M. Koper, Electrocatalytic reduction of nitrate on tin-modified palladium electrodes, Electrochim. Acta. 140 (2014) 518-524. doi:10.1016/j.electacta.2014.06.011.

[15] K. Shimazu, R. Goto, S. Piao, R. Kayama, K. Nakata, Y. Yoshinaga, Reduction of nitrate ions on tin-modified palladium thin film electrodes, J. Electroanal. Chem. 601 (2007) 161-168. doi:10.1016/j.jelechem.2006.11.005. 
[16] M. Motahar Hossain, K. Nakata, T. Kawaguchi, K. Shimazu, Reduction of nitrate on electrochemically pre-reduced tin-modified palladium electrodes, J.

Electroanal. Chem. 707 (2013) 59-65. doi:10.1016/j.jelechem.2013.08.015.

[17] K. Tada, K. Shimazu, Kinetic studies of reduction of nitrate ions at Sn-modified Pt electrodes using a quartz crystal microbalance, J. Electroanal. Chem. 577 (2005) 303-309. doi:10.1016/j.jelechem.2004.11.039.

[18] E.B. Molodkina, M.R. Ehrenburg, Y.M. Polukarov, A.I. Danilov, J. Souza-Garcia, J.M. Feliu, Electroreduction of nitrate ions on $\mathrm{Pt}(111)$ electrodes modified by copper adatoms, Electrochim. Acta. 56 (2010) 154-165. doi:10.1016/j.electacta.2010.08.105.

[19] K. Nakata, Y. Doi, S. Kubota, K. Shimazu, Reduction of nitrite on tin-modified noble metal electrodes, J. Electroanal. Chem. 647 (2010) 187-193. doi:10.1016/j.jelechem.2010.06.003.

[20] T. Chen, H. Li, H. Ma, M.T.M. Koper, Surface Modification of Pt(100) for Electrocatalytic Nitrate Reduction to Dinitrogen in Alkaline Solution, Langmuir. 31 (2015) 3277-3281. doi:10.1021/acs.langmuir.5b00283.

[21] J. Souza-Garcia, E.A. Ticianelli, V. Climent, J.M. Feliu, Nitrate reduction on Pt single crystals with Pd multilayer, Electrochim. Acta. 54 (2009) 2094-2101. doi:10.1016/j.electacta.2008.08.059.

[22] C. Milhano, D. Pletcher, The electrodeposition and electrocatalytic properties of copper-palladium alloys, J. Electroanal. Chem. 614 (2008) 24-30. doi:10.1016/j.jelechem.2007.11.001.

[23] M.C. Figueiredo, J. Solla-Gullón, F.J. Vidal-Iglesias, V. Climent, J.M. Feliu, Nitrate reduction at Pt(1 000$)$ single crystals and preferentially oriented nanoparticles in neutral media, Catal. Today. 202 (2013) 2-11. doi:10.1016/j.cattod.2012.02.038. 
[24] P. Rodriguez, F.D. Tichelaar, M.T.M. Koper, A.I. Yanson, Cathodic Corrosion as a Facile and Effective Method To Prepare Clean Metal Alloy Nanoparticles, J. Am. Chem. Soc. 133 (2011) 17626-17629. doi:10.1021/ja208264e.

[25] W. Siriwatcharapiboon, Y. Kwon, J. Yang, R.L. Chantry, Z. Li, S.L. Horswell, M.T.M. Koper, Promotion Effects of Sn on the Electrocatalytic Reduction of Nitrate at Rh Nanoparticles, ChemElectroChem. 1 (2014) 172-179. doi:10.1002/celc.201300135.

[26] Q. Wang, X. Zhao, J. Zhang, X. Zhang, Investigation of nitrate reduction on polycrystalline Pt nanoparticles with controlled crystal plane, J. Electroanal. Chem. 755 (2015) 210-214. doi:10.1016/j.jelechem.2015.08.005.

[27] J. Shen, Y.Y. Birdja, M.T.M. Koper, Electrocatalytic Nitrate Reduction by a Cobalt Protoporphyrin Immobilized on a Pyrolytic Graphite Electrode, Langmuir. 31 (2015) 8495-8501. doi:10.1021/acs.langmuir.5b00977.

[28] Y. Chen, H. Zhu, M. Rasmussen, D. Scherson, Rational Design of Electrocatalytic Interfaces: The Multielectron Reduction of Nitrate in Aqueous Electrolytes, J. Phys. Chem. Lett. 1 (2010) 1907-1911. doi:10.1021/jz1005253.

[29] M. Duca, S. Khamseh, S.C.S. Lai, M.T.M. Koper, The Influence of Solution-Phase $\mathrm{HNO}_{2}$ Decomposition on the Electrocatalytic Nitrite Reduction at a Hemin-Pyrolitic Graphite Electrode, Langmuir. 26 (2010) 12418-12424. doi:10.1021/la101172f.

[30] T. Yoshioka, K. Iwase, S. Nakanishi, K. Hashimoto, K. Kamiya, Electrocatalytic Reduction of Nitrate to Nitrous Oxide by a Copper-Modified Covalent Triazine Framework, J. Phys. Chem. C. 120 (2016) 15729-15734.

doi:10.1021/acs.jpcc.5b10962.

[31] C.M. Cordas, A.G. Duarte, J.J.G. Moura, I. Moura, Electrochemical behaviour of bacterial nitric oxide reductase-evidence of low redox potential non-heme $\mathrm{Fe}_{\mathrm{B}}$ 
gives new perspectives on the catalytic mechanism., Biochim. Biophys. Acta. 1827 (2013) 233-8. doi:10.1016/j.bbabio.2012.10.018.

[32] Ł. Krzemiński, L. Ndamba, G.W. Canters, T.J. Aartsma, S.D. Evans, L.J.C. Jeuken, Spectroelectrochemical Investigation of Intramolecular and Interfacial Electron-Transfer Rates Reveals Differences Between Nitrite Reductase at Rest and During Turnover, J. Am. Chem. Soc. 133 (2011) 15085-15093. doi:10.1021/ja204891v.

[33] H.J. Wijma, L.J.C. Jeuken, M.P. Verbeet, F.A. Armstrong, G.W. Canters, Protein Film Voltammetry of Copper-Containing Nitrite Reductase Reveals Reversible Inactivation, J. Am. Chem. Soc. 129 (2007) 8557-8565. doi:10.1021/ja071274q.

[34] K. Shimazu, R. Goto, K. Tada, Electrochemical Reduction of Nitrate Ions on Tin-Modified Platinum and Palladium Electrodes, Chem. Lett. 31 (2002) 204205. doi:10.1246/cl.2002.204.

[35] S. Haq, A. Hodgson, $\mathrm{N}_{2} \mathrm{O}$ adsorption and reaction at $\mathrm{Pd}(110)$, Surf. Sci. 463 (2000) 1-10. doi:10.1016/S0039-6028(00)00606-3.

[36] A. Ahmadi, E. Bracey, R. Wyn Evans, G. Attard, Anion-surface interactions: Part II. Nitrous oxide reduction as a probe of anion adsorption on transition metal surfaces, J. Electroanal. Chem. 350 (1993) 297-316. doi:10.1016/0022-0728(93)80212-Z.

[37] J. Yang, M. Duca, K.J.P. Schouten, M.T.M. Koper, Formation of volatile products during nitrate reduction on a Sn-modified Pt electrode in acid solution, J. Electroanal. Chem. 662 (2011) 87-92. doi:10.1016/j.jelechem.2011.03.015.

[38] D. Reyter, D. Bélanger, L. Roué, Optimization of the cathode material for nitrate removal by a paired electrolysis process, J. Hazard. Mater. 192 (2011) 507-513. doi:10.1016/j.jhazmat.2011.05.054. 
[39] R.I. Masel, An Experimental Test of Various Models of the Active Site for Nitric Oxide Reduction on Platinum, Catal. Rev. 28 (1986) 335-369.

doi:10.1080/01614948608082253.

[40] Q.-W. Zheng, C.-J. Fan, C.-H. Zhen, Z.-Y. Zhou, S.-G. Sun, Irreversible adsorption of Sn adatoms on basal planes of Pt single crystal and its impact on electrooxidation of ethanol, Electrochim. Acta. 53 (2008) 6081-6088. doi:10.1016/j.electacta.2008.01.078.

[41] J. Clavilier, D. Armand, S.G. Sun, M. Petit, Electrochemical adsorption behaviour of platinum stepped surfaces in sulphuric acid solutions, J. Electroanal. Chem. Interfacial Electrochem. 205 (1986) 267-277. doi:10.1016/0022-0728(86)90237-8.

[42] J. Clavilier, R. Faure, G. Guinet, R. Durand, Preparation of monocrystalline Pt microelectrodes and electrochemical study of the plane surfaces cut in the direction of the $\{111\}$ and $\{110\}$ planes, J. Electroanal. Chem. Interfacial Electrochem. 107 (1979) 205-209. doi:10.1016/S0022-0728(79)80022-4.

[43] J. Clavilier, The role of anion on the electrochemical behaviour of a $\{111\}$ platinum surface; an unusual splitting of the voltammogram in the hydrogen region, J. Electroanal. Chem. Interfacial Electrochem. 107 (1979) 211-216. doi:10.1016/S0022-0728(79)80023-6.

[44] D.J. Watson, G.A. Attard, The electro-oxidation of glucose using platinumpalladium bulk alloy single crystals, Electrochim. Acta. 46 (2001) 3157-3161. doi:10.1016/S0013-4686(01)00607-7.

[45] T.J. Schmidt, N.M. Markovic, V. Stamenkovic, P.N. Ross, G.A. Attard, D.J. Watson, Surface Characterization and Electrochemical Behavior of Well-Defined Pt-Pd $\{111\}$ Single-Crystal Surfaces: A Comparative Study Using Pt $\{111\}$ and Palladium-Modified Pt\{111\} Electrodes, Langmuir. 18 (2002) 6969-6975. doi:10.1021/la025521+. 
[46] D. Watson, G. Attard, Surface segregation and reconstructive behaviour of the (100) and (110) surfaces of platinum-palladium bulk alloy single crystals: a voltammetric and LEED/AES study, Surf. Sci. 515 (2002) 87-93.

doi:10.1016/S0039-6028(02)01811-3.

[47] N. Hoshi, K. Kagaya, Y. Hori, Voltammograms of the single-crystal electrodes of palladium in aqueous sulfuric acid electrolyte: $\operatorname{Pd}(S)-[n(111) \times(111)]$ and Pd(S)-[n(100)×(111)], J. Electroanal. Chem. 485 (2000) 55-60. doi:10.1016/S0022-0728(00)00098-X.

[48] T.B. Massalski, ed., Binary Alloy Phase Diagrams, vol. 3, 2nd ed., ASM International, 1992.

[49] J. Clavilier, R. Durand, G. Guinet, R. Faure, Electrochemical adsorption behaviour of Pt(100) in sulphuric acid solution, J. Electroanal. Chem. Interfacial Electrochem. 127 (1981) 281-287. doi:10.1016/S0022-0728(81)80488-3.

[50] V. Tripkovic, First principles study of (Cd, Hg, In, Tl, Sn, Pb, As, Sb, Bi, Se) modified $\mathrm{Pt}(111), \mathrm{Pt}(100)$ and $\mathrm{Pt}(211)$ electrodes as CO oxidation catalysts, Electrochim. Acta. 168 (2015) 370-378. doi:10.1016/j.electacta.2015.04.006.

[51] G. Stalnionis, L. Tamašauskaitė-Tamašiūnaitè, V. Pautienienè, A. Sudavičius, Z. Jusys, Modification of a Pt surface by spontaneous Sn deposition for electrocatalytic applications, J. Solid State Electrochem. 8 (2004) 892-899. doi:10.1007/s10008-004-0517-x.

[52] Y.Y. Birdja, J. Yang, M.T.M. Koper, Electrocatalytic Reduction of Nitrate on Tin-modified Palladium Electrodes, Electrochim. Acta. 140 (2014) 518-524. doi:10.1016/j.electacta.2014.06.011. 


\section{Figure Captions}

Fig. 1 CVs of unmodified (solid traces in black) and tin-modified (solid and broken traces in gray) single crystalline electrodes of (a) $\operatorname{Pt}(111)$, (b) $\operatorname{Pd}(111)$, (c) $\operatorname{PdPt}(111)$, (d) $\operatorname{Pt}(100)$ and (e) PdPt(100). The PdPt alloy single crystalline electrodes contain 3wt\% of $\mathrm{Pd}$ in Pt. The CVs were recorded at a sweep rate of $50 \mathrm{mV} \mathrm{s}^{-1}$ in $0.5 \mathrm{M} \mathrm{H}_{2} \mathrm{SO}_{4}$ under Ar.

Fig. 2 XPS spectra of the tin-modified/unmodified $\operatorname{Pt}(111), \operatorname{Pd}(111)$ and $\operatorname{PdPt}(111)$ alloy single crystalline electrodes (a) in the Pt $4 \mathrm{f}$ region and (b) in the Pd 3d region.

Fig. 3 XPS spectra of the tin-modified/unmodified Pt(100) and PdPt(100) alloy single crystalline electrodes (a) in the Pt $4 \mathrm{f}$ region and (b) in the Pd 3d region.

Fig. 4 XPS spectra of tin-modified single crystalline electrodes $(\theta \approx 1)$ in the Sn 3d region.

Fig. 5 CVs of unmodified or Sn-modified (a) $\operatorname{Pt}(111)$, (b) $\operatorname{Pd}(111)$, (c) $\operatorname{PdPt}(111)$ containing 3wt\% of Pd, (d) Pt(100) and (e) PdPt(100) containing 3wt\% of Pd. The CVs were recorded at $0.01 \mathrm{~V} \mathrm{~s}^{-1}$ in an aqueous electrolyte solution containing $0.1 \mathrm{M} \mathrm{HClO}_{4}$ and $0.1 \mathrm{M} \mathrm{NaNO}_{3}$ under Ar. The CVs in the first cycle are shown. The current density of each CV at the positive potential limit is nearly zero.

Fig. 6 CVs of unmodified (solid traces in gray) and tin-modified $\left(\theta_{\mathrm{Sn}} \approx 1\right.$; solid traces in black) single crystalline electrodes of (a) $\operatorname{Pt}(111)$, (b) $\operatorname{Pt}(100)$ and (c) $\operatorname{PdPt}(100)$. The PdPt alloy single crystalline electrodes contain 3wt\% of Pd in Pt. The CVs were recorded at a sweep rate of $50 \mathrm{mV} \mathrm{s}^{-1}$ in $0.05 \mathrm{M}$ phosphate buffered aqueous solution containing $0.1 \mathrm{M} \mathrm{NaNO}_{3}$ at $\mathrm{pH} 7.2$ under Ar. 


\section{Figures}

(a) $\mathrm{Sn} / \mathrm{Pt}(111)$

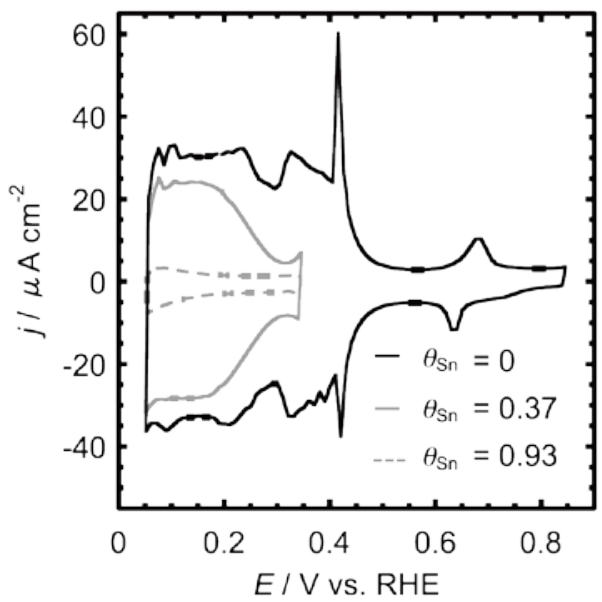

(c) $\mathrm{Sn} / \mathrm{PdPt}(111)$

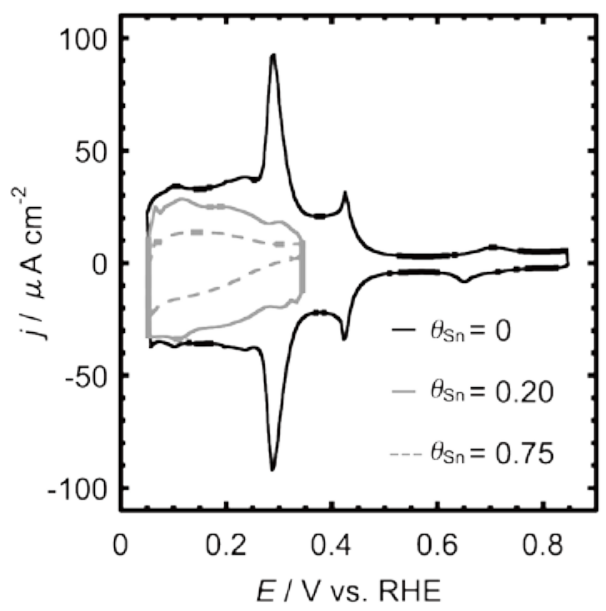

(e) Sn/PdPt(100)

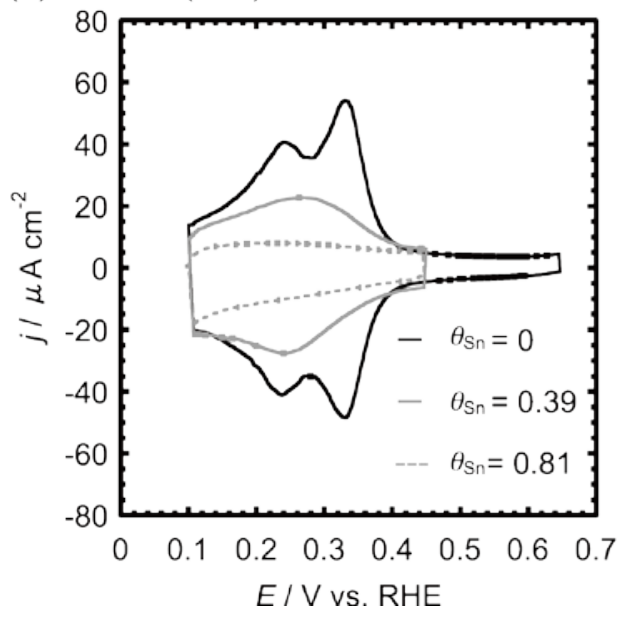

(b) $\mathrm{Sn} / \mathrm{Pd}(111)$

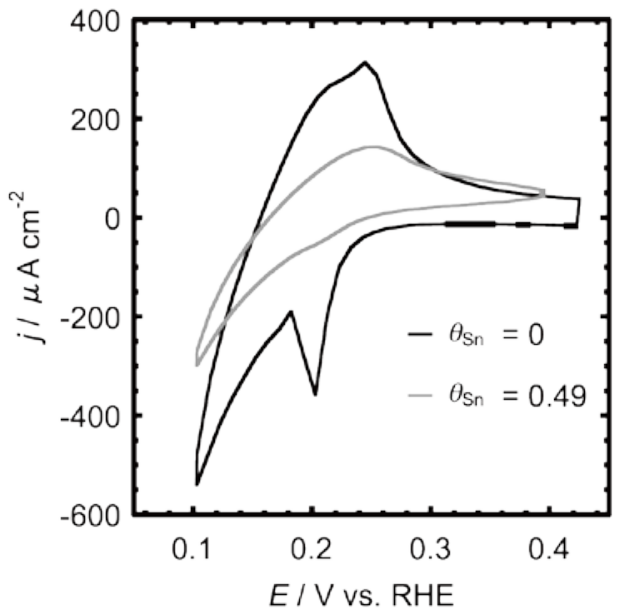

(d) $\mathrm{Sn} / \mathrm{Pt}(100)$

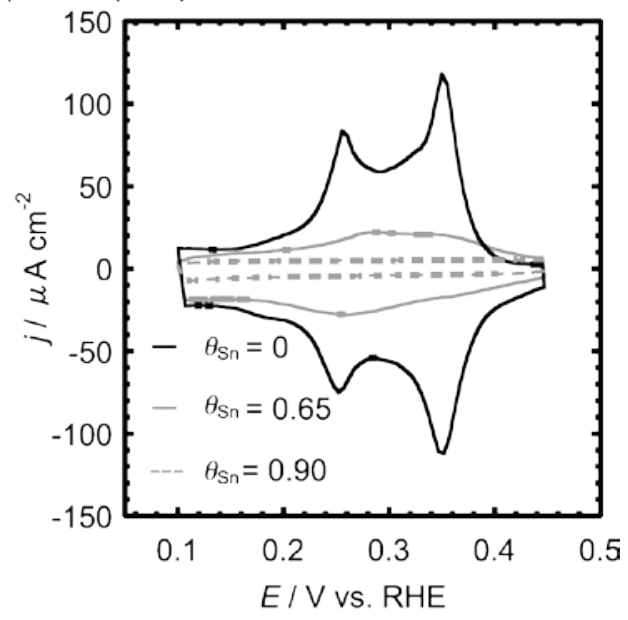

Fig. 1 
(a) Pt 4f

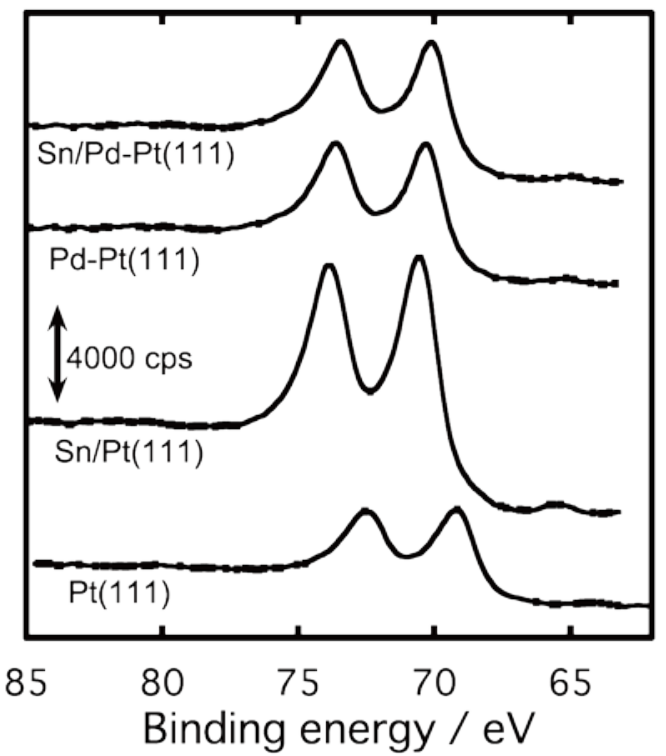

(b) Pd 3d

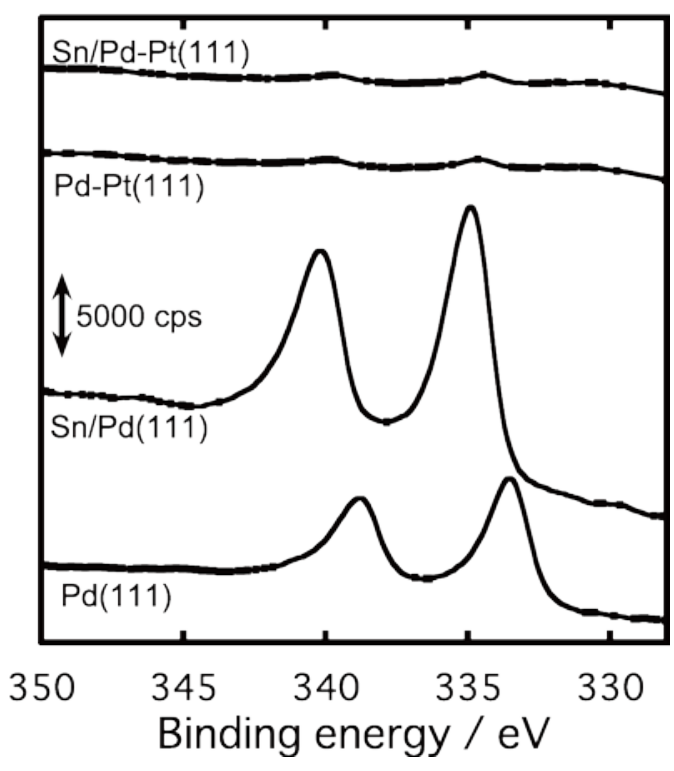

Fig. 2 
(a) Pt 4f

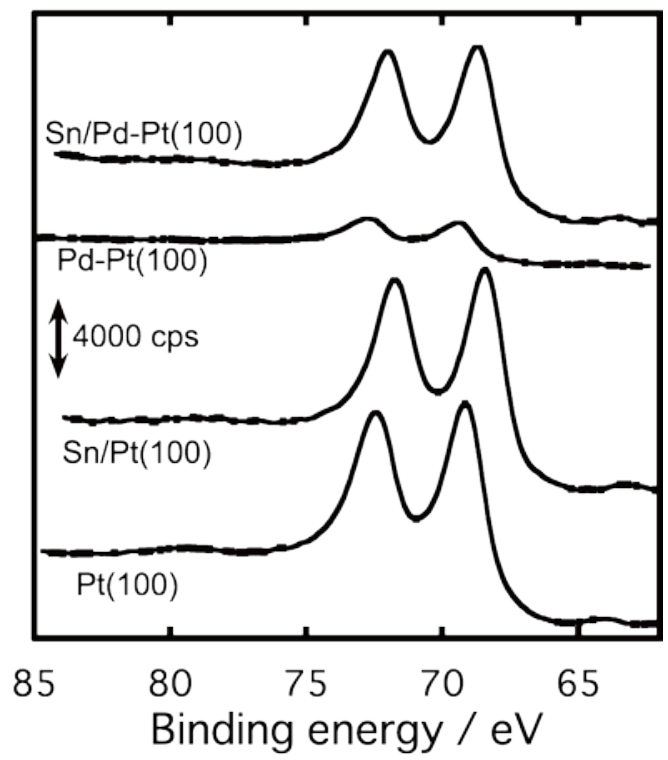

(b) Pd 3d

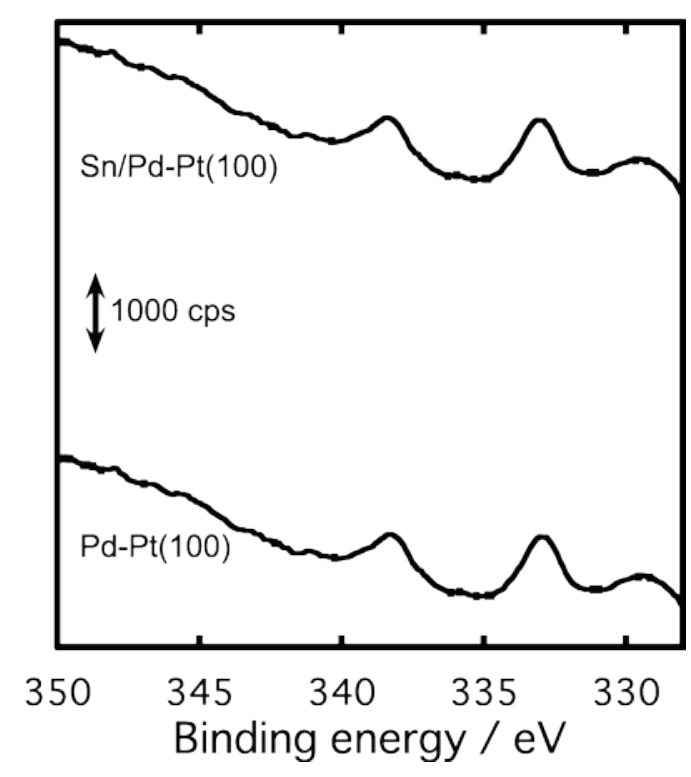

Fig. 3 
(a) $\mathrm{Sn} / \mathrm{Pt}(111)$

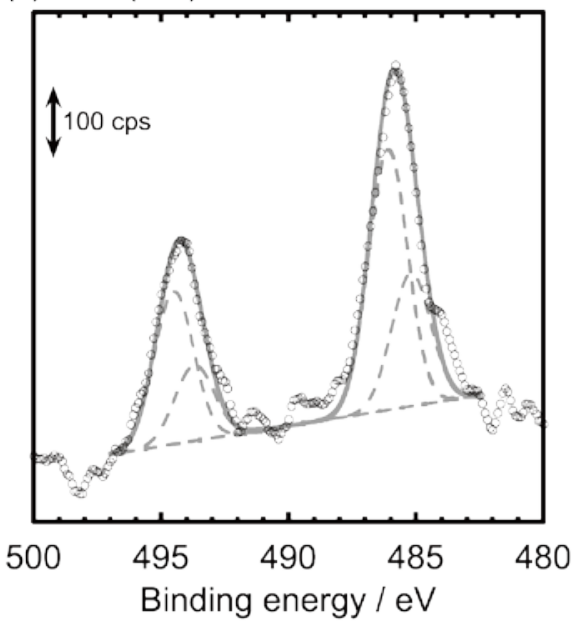

(c) $\mathrm{Sn} / \mathrm{PdPt}(111)$

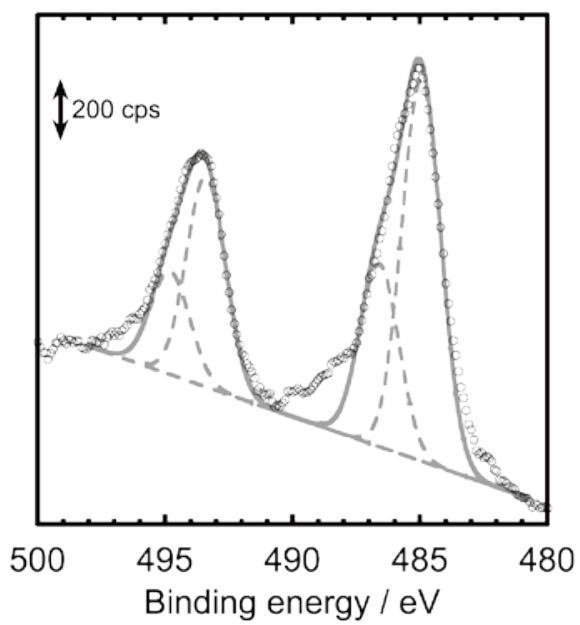

(e) $\mathrm{Sn} / \mathrm{PdPt}(100)$

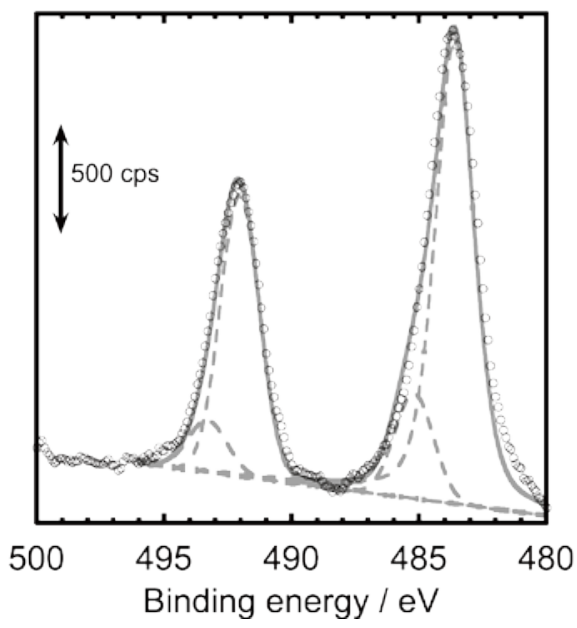

(b) $\mathrm{Sn} / \mathrm{Pd}(111)$

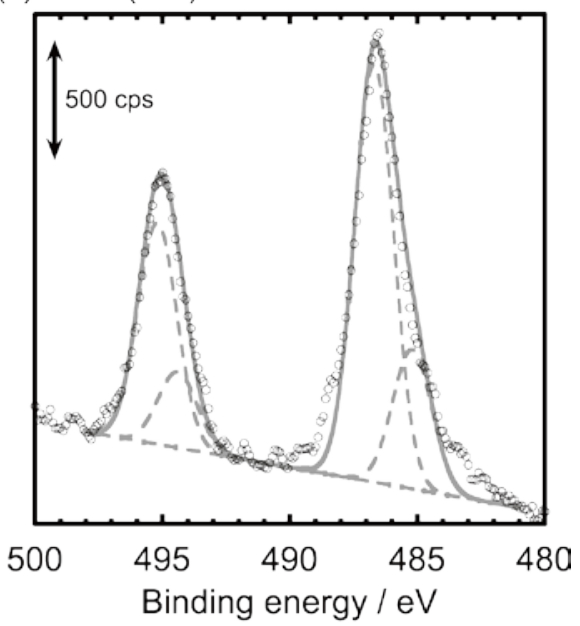

(d) $\mathrm{Sn} / \mathrm{Pt}(100)$

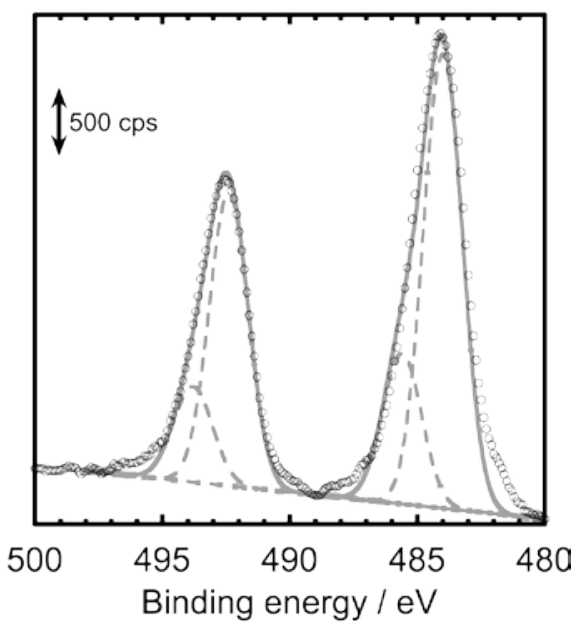

Fig. 4. 
(a) $\mathrm{Sn} / \mathrm{Pt}(111)$

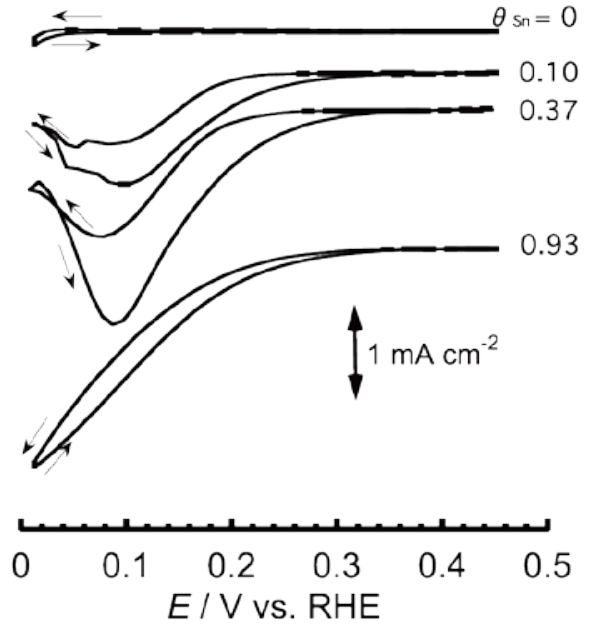

(c) $\mathrm{Sn} / \mathrm{PdPt}(111)$

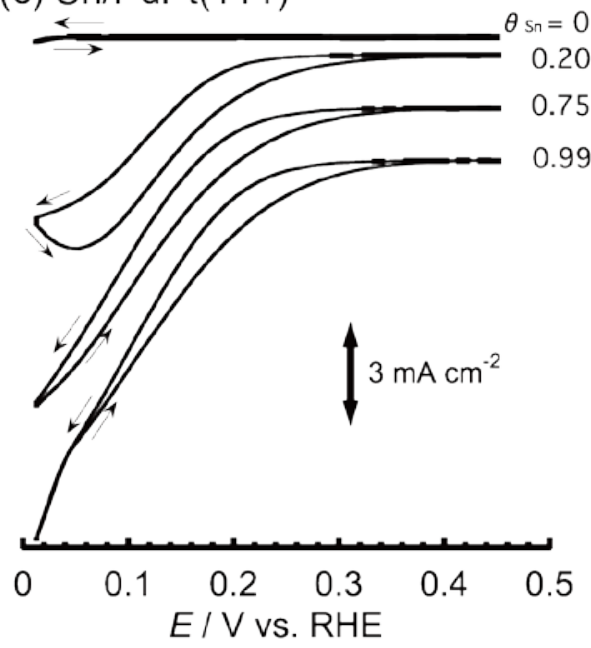

(b) $\mathrm{Sn} / \mathrm{Pd}(111)$

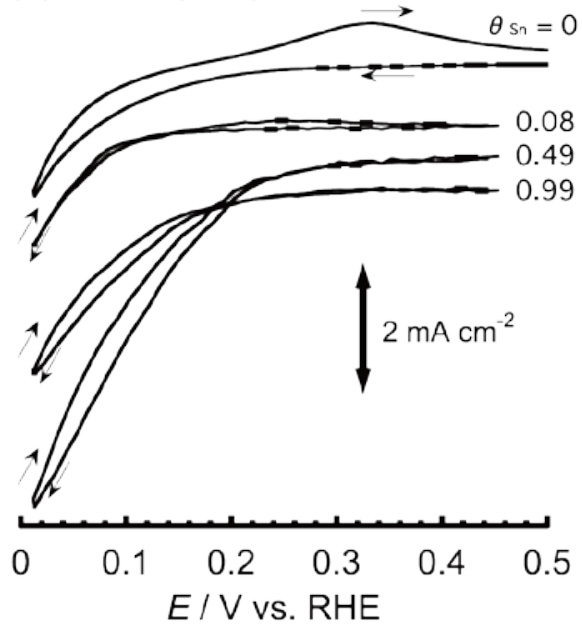

(d) $\mathrm{Sn} / \mathrm{Pt}(100)$

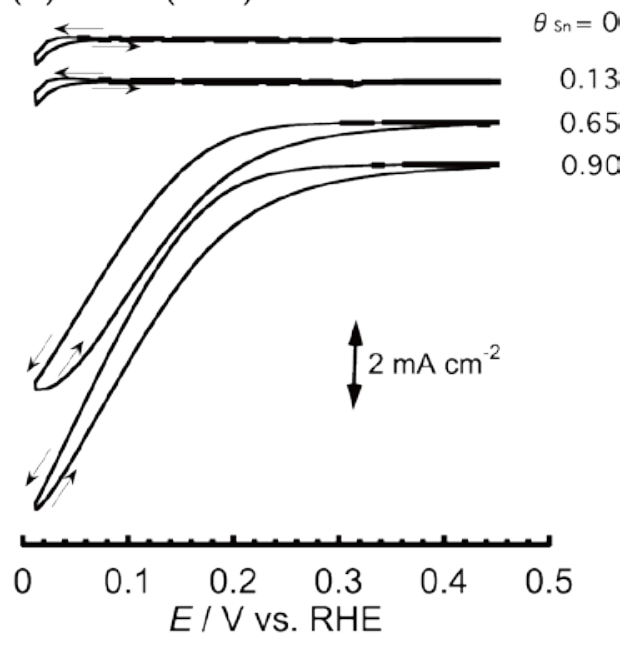

(e) Sn/PdPt(100)

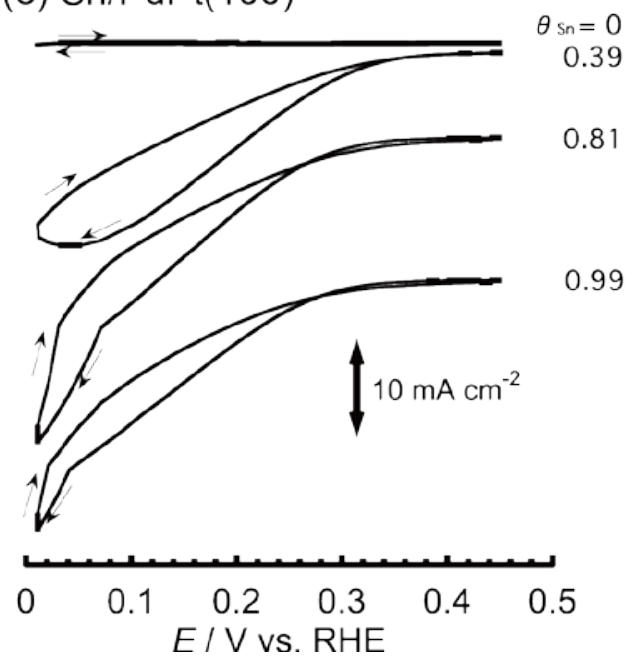

Fig. 5 


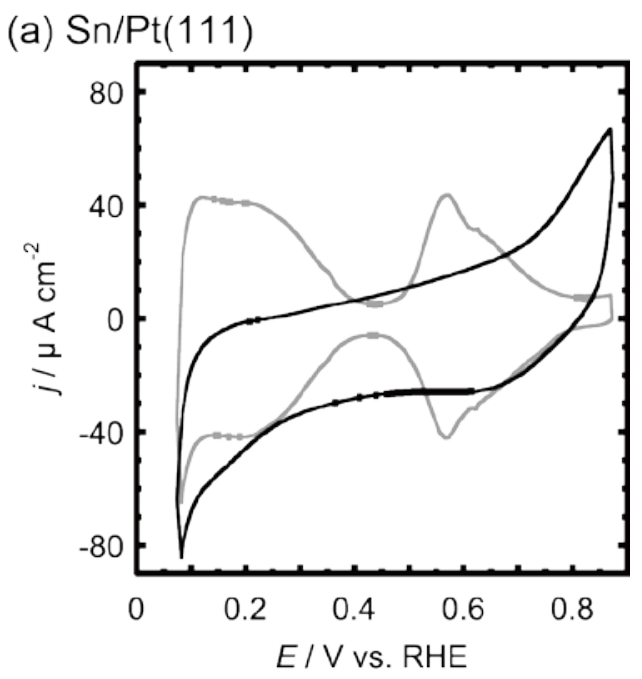

(b) $\mathrm{Sn} / \mathrm{Pt}(100)$

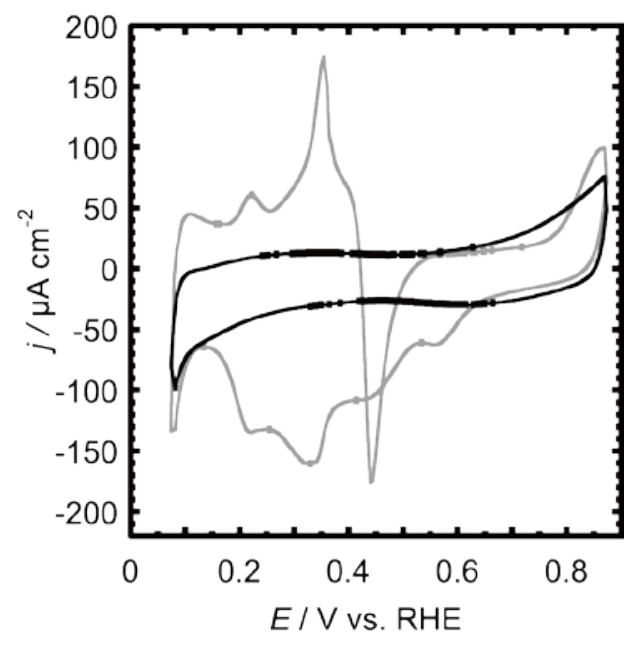

(c) $\mathrm{Sn} / \mathrm{PdPt}(100)$

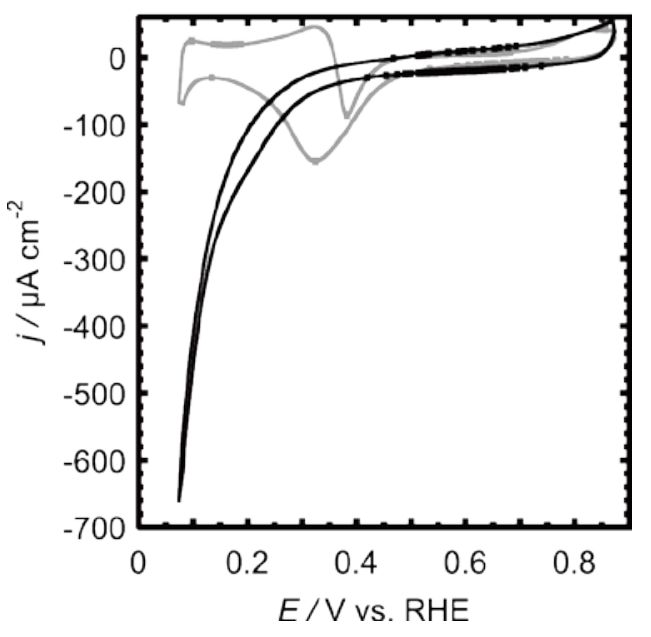

Fig. 6 


\section{Table Captions}

Table 1 The results of peak deconvolution analysis of the XPS Sn 3d peaks in Fig. 4

Table 2 Maximum current densities (j) showed by the electrodes for the nitrate reduction at $0.01 \mathrm{~V} \mathrm{~s}^{-1}$ in aqueous solution containing $0.1 \mathrm{M} \mathrm{HClO}_{4}$ and $0.1 \mathrm{M} \mathrm{NaNO}_{3}$ under $\mathrm{Ar}$ 
Table 1

\begin{tabular}{|c|c|c|c|c|c|}
\hline \multirow[t]{2}{*}{ Electrode } & \multicolumn{2}{|c|}{$\begin{array}{c}\text { Peak positions of } \\
\text { XPS Sn } 3 d_{3 / 2}\end{array}$} & \multicolumn{2}{|c|}{$\begin{array}{c}\text { Peak positions of } \\
\text { XPS Sn } 3 d_{5 / 2}\end{array}$} & \multirow[t]{2}{*}{$\operatorname{Sn}^{I I}: \mathbf{S n}^{\prime}$} \\
\hline & $\operatorname{Sn}^{\text {II }}$ & $\mathrm{Sn}^{0}$ & SnI & $\mathrm{Sn}^{0}$ & \\
\hline $\mathrm{Sn} / \operatorname{Pt}(111)$ & 494.5 & 493.7 & 486.1 & 485.2 & $66: 34$ \\
\hline Sn/Pd(111) & 495.2 & 494.4 & 486.7 & 485.2 & $75: 25$ \\
\hline $\mathrm{Sn} / \operatorname{PdPt}(111)$ & 494.9 & 493.4 & 486.1 & 484.8 & $32: 68$ \\
\hline $\mathrm{Sn} / \operatorname{Pt}(100)$ & 493.8 & 492.4 & 485.6 & 484.1 & $25: 75$ \\
\hline $\mathrm{Sn} / \mathrm{PdPt}(100)$ & 493.3 & 492.1 & 485.2 & 483.6 & $16: 84$ \\
\hline
\end{tabular}


Table 2

\begin{tabular}{|c|c|c|}
\hline$\theta_{\mathrm{sn}}{ }^{a}$ & $E / V^{b}$ & $j / \mathrm{mA} \mathrm{cm}{ }^{-2}$ \\
\hline \multicolumn{3}{|c|}{ Pt(111) } \\
\hline 0 & +0.01 & -0.2 \\
\hline 0.11 & +0.10 & $-1.6^{c}$ \\
\hline 0.37 & +0.09 & $-3.1^{c}$ \\
\hline 0.93 & +0.01 & -3.1 \\
\hline \multicolumn{3}{|c|}{$\operatorname{Pd}(111)$} \\
\hline 0 & $+0.01^{d}$ & $-2^{d}$ \\
\hline 0.08 & +0.01 & -1.7 \\
\hline 0.49 & +0.01 & -5.2 \\
\hline 0.99 & +0.01 & -2.7 \\
\hline \multicolumn{3}{|c|}{$\operatorname{PdPt(111)}$} \\
\hline 0 & +0.01 & -0.1 \\
\hline 0.20 & +0.05 & -5.5 \\
\hline 0.75 & +0.01 & -8.5 \\
\hline 0.99 & +0.01 & -10.7 \\
\hline \multicolumn{3}{|c|}{$\operatorname{Pt}(100)$} \\
\hline 0 & +0.01 & -0.6 \\
\hline 0.13 & +0.01 & -0.5 \\
\hline 0.65 & +0.01 & -6.3 \\
\hline 0.90 & +0.01 & -8.2 \\
\hline \multicolumn{3}{|c|}{$\operatorname{PdPt}(100)$} \\
\hline 0 & +0.01 & -0.2 \\
\hline 0.39 & +0.06 & -21.3 \\
\hline 0.81 & +0.01 & -32.1 \\
\hline 0.99 & +0.01 & -26.4 \\
\hline
\end{tabular}

${ }^{a}$ The surface coverage of tin over the electrode surface. ${ }^{b}$ The potential at which each electrode showed the maximum current density for nitrate reduction. ${ }^{c}$ The current density was recorded in the negative going scan. ${ }^{d}$ No current for the nitrate reduction. 